\title{
Pensar el siglo XIX desde los afectos
}

(4) Ana Peluffo ${ }^{1}$

University of California, Davis.

\section{Resumen}

Este ensayo recorre los principales aportes teóricos del giro afectivo (Sara Ahmed, Brian Massumi, Peter Stearns) y de lxs historiadorxs de la emoción (Barbara Rosenwein, William Reddy) para ver de qué manera una aproximación en clave emocional sobre los textos decimonónicos nos puede servir para desestabilizar, subvertir y/o complementar lecturas canónicas muy arraigadas en el imaginario crítico. A partir de esta historización de los afectos, este análisis se centra en la racialización y feminización de las emociones para pensar específicamente la politización del sentimentalismo y la necesidad de recobrar formas de leer el lenguaje no referencial del afecto que hemos perdido en el siglo XXI.

Palabras clave:

Giro afectivo

Emociones

Siglo XIX

Latinoamérica

\begin{abstract}
This essay goes over the main theoretical contributions of the affective turn (Sara Ahmed, Brian Massumi, Peter Stearns) and the historians of emotion (Barbara Rosenwein, William Reddy) to see how an emotional approach to nineteenth-century texts can help us destabilize, subvert and /or complement deeply rooted canonical readings in our critical imaginary. From this historization of affections, this analysis focuses on the racialization and feminization of emotions to think about the politicization of sentimentality and the need to recover ways of reading the non-referential language of affection that we have lost in the 21st century.
\end{abstract}

Keywords:

Affective turne

Emotions

19th century

Latin America.

1 Este texto es una versión adaptada de la introducción de En clave emocional. Cultural y afecto en América Latina (2016). Hemos solicitado a la autora esta versión ya que este libro inspiró el simposio "Afectos y literatura en el siglo XIX: lecturas alrededor de En clave emocional de Ana Peluffo", coordinado por Mónica Szurmuk en noviembre de 2018, en cuyo marco surgió la idea inicial de este dossier. 
En los últimos años, las emociones, los afectos y los sentimientos, relegados históricamente al campo de la psicología y la filosofía, parecen haber migrado hacia los estudios culturales y de género. Gracias en parte a los críticos del "giro afectivo" -un término acuñado por Ticineto Clough (Ticineto Clough y Halley, 2007) - que se propusieron desestabilizar el binomio jerarquizado razón-emoción, y a los historiadores y sociólogos de las emociones que, a partir de las reflexiones de Norbert Elias (2012), investigaron la forma en que estas circulan a través de diversos contextos y materiales culturales, se generó un productivo debate interdisciplinario sobre estética, afectos y política en el que aparecieron importantes zonas de contacto entre disciplinas tradicionalmente alejadas entre sí (psicología, filosofía, estudios culturales, crítica literaria, estudios de género). Aunque este "giro afectivo" se dio sobre todo en los estudios anglosajones, la reciente publicación de textos sobre la cuestión emotiva en el campo latinoamericanista (Podalsky, 2011; Reguillo, 2011: 9-15; Moraña y SánchezPrado, 2012; Macón y Solana, 2015) da cuenta de la vitalidad crítica que la teorización de los afectos ha empezado a tener en nuestro campo.

El siglo XIX quedó mayormente fuera de estos debates, pese a intervenciones aisladas que, desde la literatura sentimental o los estudios culturales, se ocuparon de investigar el rol que las emociones cumplieron en la construcción y modernización de las naciones. Uno de los objetivos de este libro es empezar a llenar ese hueco.

Se ha dicho que vivimos en un momento de achatamiento emocional, en el que se mercantilizan los afectos privados y se produce una sentimentalización de la esfera política (Illouz, 2007. 2009 [1991]; Berlant, 2004, 2008: 845-846, 2012). La medicalización de la tristeza, la represión de las emociones consideradas "negativas", la fetichización del amor y otras operaciones culturales destinadas a disciplinar el afecto en nombre del capitalismo neoliberal, forman parte del "capitalismo emocional" (Illouz, 2007) en el que nos movemos y desde el que leemos la productividad cultural del pasado. Dado que muchos artefactos decimonónicos estetizan emociones que causan incomodidad en el presente (tristeza, ennui, compasión, odio) leemos ese material afectivo con más desconfianza que interés. Una meta de este trabajo es convertir la invisibilidad cultural de las emociones en un espacio crítico de reflexión.

En la Ética demostrada según el orden geométrico, Spinoza se refiere a las emociones como "ideas confusas" derivadas de tres afectos primarios (tristeza, alegría o deseo) según disminuyan o aumenten la capacidad de obrar de los sujetos (1984 [1677]: 259). Hablar como lo hace Spinoza de la emoción como "una idea" más que un sentimiento es desmentir su carácter natural y biológico en una lectura que rescata a su vez la ambigüedad cultural y semántica de un material emotivo que él no distingue del afecto. A contrapelo de esta definición, el proyecto spinoziano incluye una jerarquización valorativa del mundo de la emoción que diferencia entre afectos "buenos" y "malos", haciendo derivar a los primeros de la alegría y a los segundos de la tristeza. De la lectura de Spinoza rescato el carácter polivalente y desordenado del afecto como un espacio híbrido siempre contaminado por la razón, al mismo tiempo que descarto la diferenciación jerárquica entre las emociones.

Ya Sianne Ngai en Ugly Feelings (2007), un libro que retoma en clave irónica la lectura spinoziana de las emociones, refuerza esa ambigüedad escurridiza de los afectos incómodos en un libro abocado a reflexionar sobre el lugar que las emociones ocupan en el capitalismo tardío. En su brillante lectura del cuento de Melville, "Bartleby, the Scrivener: A Story of Wall Street", Ngai analiza el estado aparentemente pasivo del escribiente que se resiste a participar en la economía capitalista mediante la frase "I would rather not" ("Preferiría no hacerlo"). ¿Es el gesto de Bartleby radical o reaccionario? ¿Es su pasividad una forma de depresión o un acto volitivo? Las preguntas que Ngai se plantea apuntan a la productividad cultural de la lectura del afecto, no 
solo a partir de lo que los textos afirman sino también de sus múltiples lagunas y silencios. En este sentido, la lectura de Ngai está en diálogo con la de Sara Ahmed en The Cultural Politics of Emotion (2004) cuando afirma que su objetivo no es definir las emociones (alejándose de un tipo de lectura referencial contenidista) sino estudiar las formas de su circulación y el efecto que producen en la esfera pública.

Los textos funcionan como puertas de entrada a ciertas emociones que nunca aparecen de forma aislada sino que se hibridizan y solapan con diferentes grados de intensidad. Un abordaje en este sentido procura evitar añadir una nueva antinomia (razón-emoción) a la proliferación de dualismos a la que apelamos los críticos para leer el siglo XIX: civilización vs. barbarie, público vs. privado, local vs. global, campo vs. ciudad, tradición vs. modernidad son tan solo algunos ejemplos de binomios que nos impiden leer de forma rizomática y fluida una producción cultural que se resiste en su complejidad ideológica y estética al esfuerzo ordenador de las dicotomías. Así como el modo transnacional de leer (en términos de redes y/o cosmopolitismo) nos sirve para trascender el binomio nacional vs. global, algo que ha sido perceptivamente demostrado por Susana Zanetti (2002), Claudio Maíz y Fernández Bravo (2009), Álvaro Fernández Bravo (2010: 59-85) y Pura Fernández (2015), las críticas al binomio sexo/ género por parte de las feministas de la tercera ola ponen en duda la asociación que hace el feminismo liberal del sexo con la biología, y del género con la cultura (Butler, 1990; Preciado, 2010). Aunque como afirma Eve S. Sedgwick en Touching Feeling (2003) postular una lectura no dual es incurrir, aún sin quererlo, en una forma de dualismo, este tipo de abordajes busca subvertir paradigmas que en el caso de la emoción, el sentimiento y el afecto remiten a lo que los críticos del "giro afectivo" han llamado la racionalidad de las emociones y el componente afectivo de la racionalidad. ${ }^{2}$

En los últimos años, nos hemos acostumbrado a leer el siglo XIX a partir del debate sobre la construcción y modernización de las naciones. Dentro de esta conversación, se privilegió el lado racionalmente afiliativo de los imaginarios nacionales en detrimento de su componente emocional. Mientras la teoría de la comunidad imaginada de Benedict Anderson (2013) le dio prominencia a lo escrito por oposición a lo oral y lo visual, revisiones críticas como las de Jens Andermann (2006, 2007), González-Stephan (2010), William Acree (2011) y Beatriz González-Stephan se ocuparon de recordarnos que los imaginarios nacionales se configuraron siguiendo trayectorias ópticas. Menos atención se prestó al componente afectivo de estos imaginarios y al rol que los sentimientos ocuparon en ellos. Ya en el artículo de Ernest Renan que inspiró a Anderson para desarrollar su muy citada tesis sobre la "comunidad imaginada", se hablaba del nacionalismo, no solo como un plebiscito "racional" que remitía a la elección cotidiana de los ciudadanos entre sí, sino también como un "principio espiritual" basado en el poder no referencial del afecto. En "¿Qué es una nación?" Renan hablaba de la nación como "una gran solidaridad constituida por el sentimiento de los sacrificios que se ha hecho y que aún se está dispuesto a hacer" (2000: 65) y decía que "[h]aber sufrido, gozado, esperado juntos; he ahí lo que vale más que las aduanas comunes y que las fronteras. En cuestión de recuerdos nacionales más valen los duelos que los triunfos; pues ellos imponen deberes; piden esfuerzo común" (Renan, 2000: 65).

Por la misma época en que Renan leía el nacionalismo en clave afectiva, José Martí emprendía una apología transnacional del sufrimiento en un proyecto latinoamericanista que dependía de lo que Wendy Brown llama "la fetichización de la herida" de los

2 Cecilia Macón en "Sentimus Ergo Sumus: El surgimiento del 'giro afectivo' y su impacto sobre la filosofía política” hace una genealogía de esta nueva tendencia de la crítica, particularmente en relación con los estudios de género. Macón les reconoce a los críticos de este giro (Berlant, Ahmed, Massumi y Sedgwick, entre otros) la reformulación de ciertas problemáticas en un "proyecto destinado a indagar en formas alternativas de aproximarse a la dimensión afectiva, pasional o emocional -y discutir las diferencias que pueda haber entre estas tres denominaciones- a partir de su rol en el ámbito público" (2013: 9). 
imaginarios empáticos. A diferencia de las lágrimas transatlánticas que Martí les pedía a los lectores españoles que derramaran a coro por el sufrimiento de los cubanos en El presidio político en Cuba (1871), hablaba en "Nuestra América" (1891) de "nuestras repúblicas dolorosas de América" y decía que, lo que unía a los latinoamericanos entre sí no era la lengua, la raza o el territorio geográfico sino el trauma compartido de la conquista (una herida) que desembocaba en una sensibilidad común. Cito:

Los norteamericanos posponen a la utilidad el sentimiento. -Nosotros posponemos al sentimiento la utilidad. Y si [...] ellos vendían mientras nosotros llorábamos, [...] ¿Cómo queréis que nosotros nos legislemos por las leyes con que ellos se legislan? (Martí XXI, 1963 [1891]: 16).

En este pasaje, Martí asume que el dolor es parte de la identidad latinoamericana, una comunidad continental que se construye líquidamente por oposición al carácter metálico y mercantilista de la cultura norteamericana.

Retomando la pregunta de Anderson sobre cómo explicar que alguien esté dispuesto, no tanto a matar sino a morir por una idea abstracta de nación, podríamos decir que el "amor" a la patria se construye siempre recurriendo a un abanico plural de emociones. Mientras algunas de estas (el amor ágape /la compasión) son útiles para extender radialmente las fronteras de la subjetividad nacional, o para acortar las distancias de clase y raza que separan a los ciudadanos sin trastocar las jerarquías; otras, como el odio, el miedo o el asco, son invocadas para construir barreras entre los individuos o naciones, y para alejar a los grupos sociales entre sí. Se podría sugerir incluso que el amor a la patria dependió en el siglo XIX de la estetización de emociones centrípetas que buscaban incorporar, nunca de forma igualitaria, a los grupos asimilables y aculturables a los proyectos civilizadores, y de otras centrífugas que expulsaban de forma somática a los grupos no deseados de la comunidad nacional.

En The Cultural Politics of Emotions, Ahmed afirma que la cohesión afectiva de las comunidades nacionales depende siempre de la creación de enemigos internos y/o externos, cuerpos dóciles sobre los que según ella la cultura deposita las emociones negativas que el sujeto dominante quiere expulsar de su subjetividad (2004: 49). A diferencia de otras intervenciones teóricas que plantean que las emociones van de adentro hacia afuera de los cuerpos (versión biológica) o de afuera hacia adentro (versión culturalista), Ahmed subraya la forma en que las emociones circulan entre los sujetos, depositándose y adhiriéndose a algunos cuerpos más que a otros (2004:4). En la teoría de Ahmed, las emociones no son privadas ni están ocultas en el inconsciente (como lo pensaban Freud y Darwin) sino que forman parte de la sociabilidad de los sujetos. Para aludir a la forma en que las emociones (del latín emotio = "movimiento") nos llevan a actuar de una cierta forma -ya sea mediante un alejamiento o un acercamiento hacia el objeto o sujeto que las provoca- Ahmed dice que las emociones no solo circulan entre los cuerpos, sino que crean zonas de contacto entre ellos. El roce entre los cuerpos produce, en su lectura, una sensación placentera o dolorosa que el sujeto afectivo transforma en una determinada emoción (un proceso en que la sensación recibe una etiqueta lingüística). Así como Theresa Brennan (2004) sostiene, siguiendo de cerca a David Hume, que las emociones son contagiosas, un término problemático que somatiza la emoción asociándola con una enfermedad, Ahmed puntualiza que las emociones son más "pegajosas" que contagiosas y que son intransferibles de un cuerpo a otro (2004: 10). En esta lectura, las emociones no pueden ser entendidas fuera del contexto socioafectivo en el que emergen, dado que una misma atmósfera emocional puede generar respuestas afectivas diametralmente opuestas en diferentes sujetos. 
A la hora de trazar la genealogía de estos debates es importante mencionar El proceso de la civilización (1939) de Elias, un texto seminal en el que se propone una teoría difusionista e hidráulica de las emociones. Preocupado por la forma en que la clase social opera sobre el entramado afectivo de los individuos, Elias afirma que el rechazo paulatino de las emociones bárbaras (odio, rabia, indignación) coincide con el avance de un modelo francés de sociabilidad que se globaliza en la Modernidad. Mientras que en la Edad Media los nobles hacían un uso performático de la violencia, en duelos y conflictos armados que les permitían acumular poder y tierras, a partir del siglo XVI los afectos negativos se "pacifican" y domestican en la esfera privada gracias a la monopolización de la violencia por parte del Estado. Siguiendo de cerca las ideas de Freud sobre la represión emocional en la vida civilizada, Elias dice que "ninguna sociedad puede sobrevivir sin canalizar los impulsos individuales y los afectos, sin un control muy específico de las conductas" (2012: 520). Los patrones afectivos de la sociabilidad, o lo que podríamos llamar los "estilos emocionales" de la Modernidad, se empiezan a configurar, según Elias, en el ámbito cortés europeo del siglo XVII para irradiar con posterioridad hacia otras clases sociales en un proceso imitativo que coincide con su progresiva desvalorización. ${ }^{3}$ El proceso civilizatorio fue publicado en Suiza en dos volúmenes que aparecieron en 1938 y 1939, respectivamente. ${ }^{4}$ Aunque más tarde se convertiría en un referente teórico obligado de los historiadores de la emoción, cayó rápidamente en el olvido luego de ser publicado. Tal y como lo nota Gina Zabludovsky, en el Prólogo a la edición en castellano (2012: 9-26), el hecho de que se publicara en el año del estallido de la Segunda Guerra Mundial es una ironía que no debió pasar desapercibida para los primeros lectores de la obra. En sus palabras: "Nada más paradójico y estremecedor que un texto que analiza el control de la agresividad y las 'buenas maneras' de la sociedad moderna se abra (en su segunda edición) con la dedicatoria de Elias a la memoria de sus padres, que mueren en los campos de exterminio de Auschwitz y Breslau" (1987: 12). ${ }^{5}$

La teoría de Elias continúa teniendo vigencia en parte por su temprana capacidad de complejizar el proceso civilizatorio, un proyecto no teleológico, atravesado por zonas de superposición entre la civilización y la descivilización. No obstante, su teoría fue criticada desde el campo de los estudios medievales, por establecer un contraste demasiado tajante entre los climas afectivos de la Edad Media y la Modernidad. Sin desmerecer la importancia de las reflexiones elisianas, Barbara Rosenwein objetó en su libro Emotional Communities in the Early Middle Ages (2006) la visión distópica que Elias da de la Edad Media como una época de "caos emocional" superada por la racionalidad moderna. Para combatir esta visión, Rosenwein acuñó el concepto de "comunidad emocional" y afirmó que tanto en la Premodernidad como en la Modernidad existen diversas "comunidades emocionales" (monasterios, iglesias, campos de deporte, universidades, partidos políticos) que se rigen por códigos afectivos específicos. Afirma también que al hacer un estudio de esos espacios afectivos se puede ver qué sentimientos son "valorados, devaluados e ignorados" en ellos y qué modos de expresión emocional son "estimulados, tolerados o combatidos" por

3 En la Introducción a Accidentes del alma. Las emociones en la sociedad moderna (2009), Tausiet y Amelang afirman que entre los siglos XVI y XVIII, los filósofos pensaron las emociones como "afecciones" o padecimientos que había que reprimir o controlar. Esto coincidió con la hegemonía de dos aproximaciones a la vida emocional dentro del cristianismo: por un lado, la visión estoica de las emociones como "accidentes" que alteraban el estado de calma o apatía deseado por el sujeto moderno y, por otro, la versión agustiniana de la vida afectiva que buscaba domesticar, controlar o reprimir las emociones.

4 El proceso civilizatorio se publicó por primera vez en castellano en 1987, en una edición a cargo del Fondo de Cultura Económica.

5 La teoría de Elias empezó a ser difundida en la década del setenta luego de que recibiera el premio Adorno de Sociología. En muchos sentidos se puede pensar en él como en uno de los pioneros de los estudios interdisciplinarios, ya que en los años treinta planteaba la necesidad de estudiar los procesos civilizatorios desde cruces disciplinarios entre la psicología, la sociología, la filosofía y la política, entre otras disciplinas. 
la cultura dominante (Rosenwein, 2010: 11). Algo que se deduce de sus reflexiones es que los sujetos circulan por diversos espacios y que al hacerlo acatan, transgreden o modifican los estados emocionales normativos.

En su estudio sobre la sociabilidad moderna, Elias señala que con el avance de la urbanización y la industrialización, las clases altas buscaron codificar y reglamentar los encuentros sociales para crear distancias y barreras imaginarias con las clases inferiores. Esto se hizo fomentando, por un lado, ciertas emociones en el sujeto moderno (asco, vergüenza y pudor); y por otro, prescribiendo normas de conducta y buenos modales que permitían leer en el cuerpo de los sujetos la clase social a la que pertenecían. Para Elias, la vergüenza es una emoción que contribuye a la implementación del autodominio emocional que califica como fundamental para el avance de la Modernidad. Esta visión de la retórica del control, que Elias lee en el marco de una lucha de clases, se presta también a una lectura desde el género, ya que el autocontrol del sujeto moderno (pensado por Elias como masculino) se construye en respuesta al descontrol emocional imaginado de los grupos subalternos. Sabemos, por ejemplo, que la masculinidad hegemónica, en su versión racional o viril, se construye siempre de forma relacional, como un "no ser como" los grupos socialmente devaluados, o como un distanciamiento de las mujeres, los niños y los homosexuales sobre los que la cultura proyecta las emociones que la Modernidad busca feminizar.

En respuesta a la visión que Elias tiene de la vergüenza como una emoción oculta e invisible, Sedgwick se refiere a ella como una forma de afectividad social y performática en la que el sujeto interioriza la mirada de un otro prestigioso al que busca complacer y cuya mirada le importa (2003: 36-37). De hecho, piensa en ciertos rasgos somáticos de la vergüenza (la mirada baja y el rubor) como "semáforos" sociales que señalizan "un deseo de reconstituir los puentes interpersonales" (ibídem: 36). Esta idea de la vergüenza como una emoción eminentemente social ya estaba presente en el libro de Darwin, La expresión de las emociones en los hombres y en los animales, cuando afirmaba que solo nos sonrojamos en presencia de otras personas o cuando imaginamos la mirada de un otro que nos juzga (1872: 289-319).

La vergüenza es una emoción relativamente invisible pero no ausente en el corpus latinoamericano del siglo XIX. En Facundo: Civilizacion y barbarie (1845), Sarmiento hace referencias a la vergüenza que le causaba el espectáculo de la barbarie de las villas locales del sur de Buenos Aires. Dice el sujeto narrativo, invocando dos emociones no necesariamente antitéticas:

Da compasión y vergüenza en la República Argentina comparar la colonia alemana o escocesa del sur de Buenos Aires, y la villa que se forma en el interior; en la primera las casitas son pintadas, el frente de la casa siempre aseado, adornado de flores y arbustillos graciosos; el amueblado sencillo, pero completo, la vajilla de cobre o estaño, reluciendo siempre, la cama con cortinillas graciosas y los habitantes en un movimiento y acción continuos. [...] La villa nacional es el reverso indigno de esta medalla; niños sucios y cubiertos de harapos viven con una jauría de perros; hombres tendidos por el suelo en la más completa inacción, el desaseo y la pobreza por todas partes, una mesita y petacas por todo amueblado, ranchos miserables por habitación, y un aspecto general de barbarie y de incuria los hacen notables. (Sarmiento, 1998 [1845]: 15)

La utopía civilizatoria de Sarmiento depende en este pasaje de la vergüenza como sentimiento doloroso que lo lleva a distanciarse de ciertas costumbres nacionales que no se adecuan al modelo de nación europeo que asocia con la Modernidad. En este sentido, ser civilizado es distanciarse de aquellos grupos salvajes que - aunque atractivos como objetos de estudio- necesitan ser aculturados por la cultura dominante. 
El proceso de la civilización remite en este caso a la necesidad de imponer maneras urbanas y refinadas sobre un pueblo rústico y sucio frente al que el yo letrado experimenta emociones encontradas.

En el contexto socio-afectivo de la pérdida peruana de la guerra del Pacífico entre Perú y Chile (1879-1883), González Prada siente vergüenza (o lo que él llama oprobio nacional) de los indígenas que componen el ejército peruano y que según él no han estado a la altura de la ferocidad araucana de las tropas chilenas. Pese a la distancia geográfica e histórica entre Prada y Sarmiento, la vergüenza y/o el oprobio son en ambos casos estados afectivos transitorios motivados paradójicamente por "el amor" a la nación. De lo que se trata entonces es de restituir el orgullo nacional herido mediante la transculturación de modas culturales o poses que -en el caso de Sarmiento- remiten a la necesidad de civilizar y urbanizar las "masculinidades bárbaras" (un término acuñado por Álvaro Fernández Bravo), y en el caso de Prada, de virilizar o "peruanizar" a los indígenas para que pudieran luchar en los ejércitos y dar la vida por la nación.

Así como la vergüenza se relaciona en los textos canónicos con la interiorización de una mirada europea que devalúa todo aquello que no se adapta a sus cánones, en el caso de las escritoras indigenistas del siglo XIX, el orgullo frente a una cultura andina devaluada por los proyectos de nación hegemónicos se articula con una vergüenza provocada por situaciones de violencia y acoso sexual. Desde esta perspectiva, la vergüenza hace apariciones fugaces en Aves sin nido, de Clorinda Matto de Turner, cuando la autora dice que "las mujeres que entran de mita salen mirando el suelo" (1889: 25). ${ }^{6}$ Aunque la palabra vergüenza no se menciona nunca en la novela, Matto alude a esta emoción por medio de los efectos somáticos que tiene en el cuerpo de las mujeres indígenas acosadas que bajaban la mirada, abrumadas por el peso de un delito sexual (la violación) que no se podía nombrar en el siglo XIX. Ese sentimiento de vergüenza de las mujeres racialmente otras en la comunidad imaginada de Killac las acerca a las mujeres de clase alta en la novela (las notables) que si, por un lado, apelan a la ideología del recato (una forma menor de la vergüenza asociada con el deber ser femenino en el siglo XIX) para afirmar su "decencia", por otro soportan, como sus contrapartes indígenas, la violencia doméstica a las que las someten las autoridades eclesiásticas andinas. ${ }^{7}$

Entre los múltiples debates que tienen lugar en la crítica a la hora de teorizar e historizar el afecto la cuestión denotativa ocupa un lugar privilegiado. ¿Existen diferencias entre el afecto, el sentimiento, la pasión y la emoción? ¿Es el término pathê ("pasión") que acuñó Aristóteles en la Ética Nicomaquea equivalente al concepto de emoción? ¿Es el afecto más abstracto e intenso que el sentimiento? ¿O es el afecto, como lo pensaba Spinoza, indiferenciable de lo emocional? En "Intuitionists: History and the Affective Event", Lauren Berlant define el afecto como la somatización de una intensidad epocal que equivale a "la receptividad activa del cuerpo a la intensidad del tiempo presente" (2008: 845). ${ }^{8}$

Aunque algunos críticos plantean la idea de que los afectos y las emociones son categorías indiferenciables e intercambiables (Ahmed, 2004; Greco y Stenner, 2008), 6 El término "mita” proviene del quechua y significa "turno de trabajo". Como práctica heredada de la conquista, en la que los indígenas les pagaban a los españoles un tributo en forma de trabajo, siguió vigente en el siglo XIX en condiciones cercanas a la esclavitud.

7 En el caso de Aves sin nido (1889) de Matto de Turner, me refiero a doña Petronila, mujer cusqueña de la clase alta en Killac, que es golpeada por su esposo el gobernador.

8 La definición que Berlant da de lo afectivo como un estado preverbal cercano a lo intuitivo coincide con la de Massumi. Cabe citar el siguiente pasaje: "Para los propósitos de este ensayo, mi argumento será que el afecto, la receptividad activa del cuerpo a las intensidades del presente, sumerge al sujeto en un campo histórico, y que la investigación de ese momento histórico puede iluminar las condiciones de producción de ese instante visceral" (2008: 845-846). 
el texto de Berlant postula una separación tajante entre ambos campos semánticos. En su propuesta de separar afecto y emoción, Berlant sigue a Brian Massumi quien, en la introducción a Mil mesetas, define el afecto en términos deleuzianos como una "intensidad prepersonal" y no biográfica que remite a la capacidad biopolítica de los cuerpos de afectar y ser afectados entre sí (Masshumi, en Deleuze y Guattari, 1988: $x v i)$. La idea de la afectividad como una intensidad más abstracta que los sentimientos y/o las emociones (que conformarían pese a la diferencia de matices una suerte de material afectivo etiquetado y procesado por el lenguaje) entra en diálogo asimismo con la idea del contagio afectivo desarrollada por Brennan en The Transmission of Affect (2004), una teoría en la que se piensa al sujeto como una esponja que absorbe la intensidad socio-afectiva de su entorno. Según esta autora, es recién en el siglo XIX que se sexualiza el término pasión que en la Retórica de Aristóteles alternaba casi indistintamente con la palabra sentimiento (1990: 3-4).9 Así como en los siglos XVI al XVIII "se hablaba sobre todo de afectos o pasiones" como alteraciones de la psique que sacudían momentáneamente la estabilidad del sujeto (Tausiet y Amelang, 2009: 8), la palabra sentimiento es la que circula con más frecuencia en el corpus decimonónico. ${ }^{10}$

En La expresión de las emociones (1872), un libro poco leído de Darwin que fue tempranamente traducido al castellano, este sugería que las emociones no eran culturales sino universales e innatas. Para probar que una misma expresión facial podía ser comprendida transnacionalmente por sujetos socializados en diferentes culturas, Darwin se ocupó de circular entre sus amigos fotografías posadas de estados emocionales cardinales (miedo, asco, vergüenza, odio) para ver si eran capaces de reconocer una cierta gestualidad. La tesis de Darwin consistía en que el lenguaje de las emociones faciales era ingénito y biológico, algo que buscaba demostrar a partir de la inclusión en el libro de fotografías del médico francés Guillaume Duchenne. Otra conclusión a la que llegaba Darwin era que la somatización de ciertas emociones en los seres humanos y los animales postulaba la posibilidad de que el hombre hubiera existido en forma animal. ${ }^{11}$ La teoría de Darwin sobre la universalidad de las emociones entró rápidamente en desuso y fue refutada por Margaret Mead, en Coming of Age in Samoa (1928), un libro en el que se demostraba que había emociones que eran culturalmente específicas y que no se prestaban a una lectura transnacional. ${ }^{12}$ Esta idea fue retomada por Catherine Lutz en Unnatural Emotions (1988) cuando sugería, a partir de una cuidadosa etnografía de la cultura ifaluk, que existían estados afectivos locales que no pueden ser traducidos a los estándares afectivos occidentales. Entre los muchos ejemplos que Lutz daba de emociones que no tienen equivalente en la cultura occidental figuran la palabra waiâpi que remite a un estado de trance o euforia provocado por una experiencia musical y la emoción fago que remite en esa cultura a un estado amalgamado que combina amor, compasión y tristeza (Lutz, 1988: 82).

9 Convencer y emocionar eran actos finamente imbricados en la retórica aristotélica ya que la persuasión dependía de la capacidad del hablante de apelar a una amplia gama de emociones (deseo, miedo, coraje, envidia, alegría, amor, odio, celos y compasión, entre otras) (1990: 96).

10 La palabra "afecto" como sinónimo de emoción circula con insistencia a lo largo del siglo XIX. Ver "Afectos íntimos" de Esteban Echeverría o las cartas de Gertrudis Gómez de Avellaneda a Ignacio de Cepeda donde el sujeto epistolar frecuentemente se despide de su amante "con un afecto puro y tierno" (1969: 144). También González Prada habla de afectos en sus poemarios (1985: 101).

11 Darwin menciona asimismo la función evolutiva del asco que, paradójicamente, distingue a los humanos de los animales. Esta emoción que Darwin ilustra mediante una fotografía de un hombre a punto de vomitar busca protegernos, según este pensador, de sustancias que puedan poner en peligro nuestra subsistencia. Para un estudio cultural del asco que toma en cuenta el efecto negativo que puede tener en la sociabilidad ver Miller.

12 El libro de Mead es un estudio comparativo sobre culturas juveniles de Samoa y Estados Unidos. A partir de un cuidadoso trabajo etnográfico, la autora demuestra que "la adolescencia no es necesariamente una época de tensión y dificultades, sino que son las condiciones culturales las que la determinan" (1928: 234). Otro punto que demuestra la autora es que el conflicto emocional de la niña adolescente no está contenido dentro de su cuerpo sino que es la civilización la que ve con sospecha su sexualización. 
En Ugly Feelings, Ngai llega al extremo de postular nuevos estados afectivos para problematizar la referencialidad de cualquier término que aluda a una emoción específica. Un ejemplo de esto es su resemantización del concepto de lo sublime kantiano que ella descarta para acuñar un nuevo término, "stuplimity", es decir, una "experiencia estética en la que se unen de forma paradójica el deslumbramiento y el aburrimiento" (Ngai, 2005: 271). Algo que podemos extrapolar de la lectura de Ngai sobre las emociones negativas (irritación, ansiedad, envidia) es que ciertos estados afectivos del pasado (lo sublime, el ennui o el "ressentiment" niezcheano que no es exactamente envidia o rabia) son intraducibles a la época actual, y que las emociones que asociamos con el capitalismo tardío (ataques de pánico, trastornos de ansiedad, estrés) no existían como "estructuras de sentimiento" (Williams, 1977: 128-135) en el siglo XIX, o al menos si existían circulaban con otros nombres.

En el debate sobre la universalidad o especificidad cultural de las emociones importa destacar asimismo las intervenciones del psicólogo norteamericano Paul Ekman (2003) quien, aunque en un principio se propuso, como Mead, refutar las teorías universalistas de Darwin, finalmente acabó corroborando muchas de sus hipótesis. Mediante un conocido test de las emociones diseñado para medir la capacidad de los sujetos para leer estados afectivos en las expresiones faciales, lo que Goleman (1994) llamaría más tarde "inteligencia emocional", Ekman descubrió que los sujetos de diversas culturas eran capaces de identificar visualmente los estados emocionales primarios y de asociar la foto de un estado afectivo con su nomenclatura. Su teoría de las microexpresiones faciales, es decir expresiones inconscientes que traicionan al propio sujeto que no sabe que las está manifestando, se convirtió en una herramienta fundamental de la psiquiatría, el mercado y los sistemas de vigilancia neoliberales. La peligrosa cercanía del trabajo de Ekman con la frenología del siglo XIX resultó atractiva para agencias gubernamentales estadounidenses y para el FBI que se interesaron en el uso que se podía hacer de esta teoría en la lucha contra el terrorismo. La popularidad de la teoría de Ekman se reflejó no solo en su función como asesor emocional de ciertas películas de dibujos animados, abocadas a representar visualmente diversos estados afectivos (Toy Story e Inside Out) sino también en la serie televisiva Lie to Me (Miénteme) en la que un detective de las emociones usa su conocimiento de las microexpresiones faciales para leer la culpabilidad o la inocencia de los sujetos en la gestualidad de sus cuerpos.

Un proyecto común de los pensadores del llamado "giro afectivo" es la tendencia a desconfiar de las emociones canónicas (felicidad, amor, compasión) y reevaluar aquellas consideradas negativas por la cultura dominante (indignación, resentimiento, envidia). Esto es algo que Macón nota perceptivamente en un artículo pionero sobre el tema titulado "Sentimus ergo sumus" en el que lee las teorías del "giro afectivo" como una respuesta a disputas internas dentro del campo de los estudios de género, y en el que registra su impacto político-filosófico, negando que el término sea "un nuevo abuso de la mercadotecnia filosófica" (2013: 2). ${ }^{13}$ En El consumo de la utopía romántica (1997) Illouz demuestra que el modelo hegemónico del amor en el capitalismo tardío no es inmune a la lógica de la mercantilización neoliberal, una idea a la que también se pliega Butler en su conocido ensayo sobre el amor, titulado significativamente "Doubting Love", en el que habla del amor heteronormativo como una forma de intercambio. Por otro lado, en The Promise of Happiness (2010), Ahmed reflexiona sobre el carácter ideológicamente opresivo de la felicidad en lo que Byung-Chul Han llama la cultura contemporánea del "me gusta" y las caritas sonrientes (2015:30-31).

13 Ver también la excelente introducción al libro de Macón y Solana, Pretérito indefinido. Afectos y emociones en las aproximaciones al pasado (2015) que, aunque recibí tardíamente en momentos en que este libro ya estaba escrito, amplía y profundiza muchas de las cuestiones teóricas planteadas por Macón en "Sentimus ergo sumus" (2013). 
Si los críticos del giro afectivo asocian el amor y la felicidad con ideologías hegemónicas que causan desigualdad y opresión, no menos importante es el cuestionamiento que Berlant hace en El corazón de la nación (2011) de la compasión y los imaginarios empáticos a partir de Uncle Tom's Cabin (1851) de Harriet Beecher Stowe, una novela que estuvo en el centro de los debates sobre el sentimentalismo norteamericano.

En "Feminism Unbound: Revolution, Mourning, Politics" publicado en Edgework: Critical Essays on Knowledge and Politics, Wendy Brown analiza lo que ella llama la crisis del feminismo al plantearse la siguiente pregunta: ¿se puede pensar el feminismo más allá del binomio sexo/género? Brown habla del feminismo como un espacio en duelo por la pérdida de sus aspiraciones utópicas, un movimiento político que sobrevive pese a la ausencia de un horizonte revolucionario (Brown, 2005: 169). La idea del feminismo herido me parece perceptiva como una forma de explicar las tensiones internas dentro del campo. Sin embargo, el diagnóstico de Brown se contradice con un resurgimiento del feminismo en las nuevas generaciones, que en los últimos años lo han recuperado como parte de su identidad. En este caso hay que distinguir entre lo que sucede con el feminismo en Estados Unidos y lo que está pasando en América Latina donde la violencia de género (que en algunos países se traduce en altos índices de femicidios) continúa demostrando la necesidad de mantener viva la categoría "mujer" como motor del activismo feminista. Al margen de las discrepancias ideológicas dentro del feminismo, sin embargo, existen muchas zonas de contacto entre el feminismo posestructuralista (Butler, Brown), el feminismo de la segunda ola (Nussbaum, 2001, 2004) y las propuestas del giro afectivo. Aunque estas críticas tienen ideas muy disímiles sobre lo que debería ser, o no, el feminismo coinciden en la necesidad de desjerarquizar el binomio emoción/razón y de pensar en ciertas emociones como construcciones culturales que contribuyen a reforzar las jerarquías.

Uno de los problemas del giro afectivo tal y como se da en los estudios culturales es lo que Rosenwein llama su "presentismo", es decir la falta de interés en historizar las emociones y sus complicadas genealogías. En este sentido, es importante mencionar a los historiadores de la emoción que en los últimos años han retomado algunas de las ideas de Elias y Williams sobre emoción, Modernidad e ideología. Aunque la relación interdisciplinaria entre la psicología, la historia y la sociología no ha sido fácil, Peter Stearns (1989), William Reddy (2001) y Rosenwein (2006) proponen revisar el concepto de "estructura de sentimiento" de Willliams mediante la incorporación de paradigmas relacionados. Así como para Reddy en The Navigation of Feeling (2001), los "refugios emocionales" son espacios culturales o políticos desde los que los ciudadanos combaten la regulación afectiva a la que son sometidos por la cultura, Rosenwein señala que la palabra "régimen", apropiada según ella para discutir "el deber ser emocional" de gobiernos dictatoriales o despóticos, no es transferible a climas afectivos actuales que son ajenos a esa realidad traumática.

Uno de los objetivos de abordar el corpus del siglo XIX latinoamericano desde esta perspectiva es historizar los estados emocionales del pasado y sus complicados procesos de estetización. ¿De qué manera las emociones desestabilizan el binomio de civilización/barbarie? ¿De qué modo los artefactos culturales interactúan con las constelaciones emocionales normativas dentro de las que surgen y a las que tratan de moldear? ¿En qué momento se pasa de lo que Beatriz Sarlo llama la lectura identificativo-emocional a la lectura irónica, paródica, o incluso somática, de las emociones? Y, finalmente, ¿cómo hacen los grupos marginales para resemantizar el exceso emocional que la cultura deposita sobre sus cuerpos?

En una entrevista que Manuel Cruz le hace a Victoria Camps con motivo de la publicación de El gobierno de las emociones (2011), este le pregunta —refiriéndose al título del libro- si piensa que las emociones deben ser gobernadas por la razón. ¿Alude el 
título de su libro al carácter indomable de las emociones que la Modernidad busca racionalizar? Camps reconoce que el título incluye, tal vez a pesar suyo, una jerarquía entre razón y emoción, y dice que lo que busca sugerir es que las emociones en estado puro no nos sirven y que necesitan ser educadas o guiadas por la razón. Apoyándose en una tradición filosófica que reconoce el valor de las emociones para la cultura occidental (Hume, Spinoza, Aristóteles), dice que las emociones no son nunca buenas o malas sino que existe un buen o un mal uso de ellas dependiendo de cuánto contribuyan o no a lo que Aristóteles llamaba la eudaimonia o el florecimiento humano. A manera de ejemplo, Camps alude a la emoción del miedo que aunque tiene un lado positivo a la hora de protegernos de situaciones peligrosas incitándonos a la cautela, puede ser utilizada por los gobiernos totalitarios para movilizar a los ciudadanos en contra de ciertos grupos construidos como violentos o amenazantes.

En el campo latinoamericano, la frase de González Prada, "guerra al sentimiento culto divino a la razón" que Mariátegui coloca como epígrafe a uno de los capítulos de Siete ensayos de interpretación de la realidad peruana invoca en muchos sentidos el carácter atormentado y semánticamente denso de una Modernidad que feminiza ciertas emociones (pudor, compasión, amor, miedo) y viriliza otras (orgullo, indignación, ira). La cruzada antisentimental de González Prada se hace en el contexto bélico de la Guerra del Pacífico (1879-1883) y en nombre de una masculinidad helénica cuyo orgullo masculino había sido herido por la pérdida de la guerra. Prada coincide con Martí a la hora de asociar la masculinidad sentimental con la figura orientalista de Boabdil, un personaje despreciado en la cultura latinoamericana por haber llorado con lágrimas de mujer lo que no pudo defender como un hombre. Sin embargo, así como en ambos casos el proceso de virilización de ciertas emociones coincide con un deseado estoicismo que establece una relación oximorónica entre masculinidad y sentimentalismo, la lectura a contrapelo de sus obras demuestra que es justamente el pánico letrado ante los procesos de democratización cultural lo que despierta la necesidad de combatir y feminizar las emociones.

Sería tentador, entonces, establecer una cronología cultural del siglo XIX que trazara un recorrido que fuera desde el desborde afectivo del paradigma romántico (tal y como aparece en Gertrudis Gómez de Avellaneda o en Flora Tristán) hasta la visión irónica de las emociones que empiezan a surgir hacia fines de siglo en los ensayos de González Prada o en la poesía de Darío, para dar solo algunos ejemplos. Cuando Darío dice en "Lo fatal", "Dichoso el árbol que es apenas sensitivo/ y más la piedra duda, porque esa ya no siente," asocia la felicidad con un emergente estoicismo cuya desconfianza hacia todo lo emocional se consolida en América Latina con el avance de las vanguardias. Las lágrimas masculinas que tienen un estatus sagrado en María de Jorge Issacs (1867), empiezan a ser "cuadradas" en Alfonsina Storni, ${ }^{14}$ parodiadas en "El cocodrilo" de Felisberto Hernández (1971), o reprimidas y combatidas en Martí y Prada (para citar algunos ejemplos). En esta teleología se podría mencionar asimismo la atracción que el naturalismo positivista experimenta por emociones centrífugas (asco, desprecio) que expulsan a los sujetos indeseables de las naciones una vez que estas ya han sido consolidadas. Me refiero en el caso argentino a novelas como En la sangre (1887) de Eugenio Cambaceres e Inocentes o culpables (1884) de Juan A. Argerich en las que los inmigrantes italianos, convertidos en objetos de desprecio y asco, son expulsados del mundo intelectual de la racionalidad. Esa misma emoción se usa en Martín Fierro para establecer una jerarquía entre las masculinidades bárbaras y para construir una barrera entre los gauchos y los indígenas: "Esos indios vagabundos, /

14 En "Cuadrados y ángulos", Storni, geometriza la lágrima para hablar de la manera en que las mujeres interiorizan un deber ser social al que les es difícil oponerse. "[...] Las gentes ya tienen el alma cuadrada,/ ideas en fila/y ángulo en la espalda;/ yo misma he vertido/ ayer una lágrima,/ Dios mío, cuadrada". 
Con repunancia me acuerdo,-/ Viven lo mesmo que el cerdo/ En esos toldos inmundos" (2001 [1872]: 292).

Más productivo, sin embargo, me parece invocar el análisis sincrónico que Williams propone como lente de aproximación a las dinámicas culturales del pasado para estudiar la formación tectónica de estilos emocionales hegemónicos, emergentes y residuales. Siguiendo y ampliando esta idea, se podría sugerir incluso que, en el siglo XIX latinoamericano diferentes y antitéticos paradigmas emocionales conviven, se cruzan y se entrelazan de forma casi rizomática impidiendo su periodización. Modelos sentimentales, cínicos y estoicos de subjetividad circulan dentro del corpus literario de un mismo autor/a y, a veces, dentro de un mismo texto. En este sentido, el avance de la retórica del control que Elias asocia con la Modernidad nunca fue rotundo en América Latina y convivió siempre con momentos de gran inestabilidad emocional. En los casos de Martí o González Prada, para volver a los ejemplos mencionados, se aboga por un modelo de masculinidad antisentimental, viril y estoico desde los ensayos, al mismo tiempo que se usa el espacio de la poesía para mantener vivas a nivel residual las emociones "débiles" que tan problemáticas resultan para la subjetividad masculina.

En conjunto, las lecturas que aquí se proponen arrojan una nueva mirada sobre artefactos culturales que han sido abordados en su gran mayoría desde perspectivas alegóricas, fundacionales o somáticas. El estudio del afecto, tanto en su vertiente abstracta y no referencial como en la aproximación crítica a emociones canónicas y anticanónicas, busca renovar el campo de la crítica desde una lente poco explorada en los estudios del siglo XIX. Iniciar nuevas líneas de debate sobre el rol que el afecto ocupa en las culturas latinoamericanas del siglo XIX es uno de los objetivos que me he planteado. 


\section{Q Bibliografía}

" Acree, W. G. (2011). Everyday Reading: Print Culture and Collective Identity in the Río de la Plata, 1780-1910. Nashville, Vanderbilt University Press.

"Ahmed, S. (2004). The Cultural Politics of Emotion. Londres, Edinburgh Press.

»----. (2012). The Promise of Happiness. Durham, Duke University Press.

»Andermann, J. (2007). The Optic of the State: Visuality and Power in Argentina and Brazil. Pittsburgh, University of Pittsburgh Press.

"Anderson, B. (2013). Comunidades imaginadas: Reflexiones sobre el origen y la difusión del nacionalismo. México, FCE.

"Argerich, J. A. (1884). Inocentes o culpables.

»Aristóteles (2007). Retórica. Rodríguez Mondino, C. (trad.). Buenos Aires, Gradifco.

» Beecher Stowe, H. (1851). Uncle Tom's Cabin.

»Berlant, L. (2004). Compassion: The Culture and Politics of an Emotion. Chicago, University of Chicago Press.

»----. (2008) Intuitionists: History and the Affective Event. En American Literary History, 20 (invierno).

»----. (2012). El corazón de la nación: Ensayos sobre política y sentimentalismo. México, FCE.

»Brennan, T. (2004). The Transmission of Affect. Ithaca, Cornell University Press.

"Brown, W. (2005). Edgework. Critical Essays on Knowledge and Politics. Princeton, Princeton University Press.

» Butler, J. (1990). Gender Trouble. Feminism and the Subversion of Identity. Londres, Routledge.

"Cambaceres, E. (1887). En la sangre.

"Camps, V. (2011). El gobierno de las emociones. Barcelona, Herder.

»Darwin, C. (2010 [1872]). The Expression of Emotions in Man and Animals. Londres, John Murray.

»Deleuze, G. y Guattari, F. (1988). Mil mesetas: Capitalismo y esquizofrenia. Pérez Vázquez, J. (trad.). Valencia, Pre-Textos.

»Ekman, P. (2003). Emotions Revealed: Recognizing Faces and Feelings to Improve Communication and Emotional Life. Nueva York, Times Books.

»Elias, N. (2012 [1987]). El proceso de la civilización. Investigaciones sociogenéticas y psicogenéticas. García Cotarelo, R. (trad.). Zabludovsky, G. (prefacio). 1ํㅡㄹ 1938-1939. México, FCE.

»Fernández Bravo, Á. (2010). Políticas del cuerpo en la frontera, Argentina y Brasil, c. 188o. En Peluffo, A. y Sánchez Prado I. (eds.). Entre hombres: masculinidades del siglo XIX en América Latina. Madrid, Iberoamericana/Vervuert.

" Goleman, D. (1994). Emotional Intelligence. Why It Can Matter More Than IQ. Nueva York, Bantam Books. 
" Gómez de Avellaneda, G. (1969). Diario de Amor/Autobiografía/Cartas a Ignacio de Cepeda. La Habana, Instituto del libro.

» González Prada, M. (1985). Páginas libres/Horas de lucha. Barcelona, Biblioteca Ayacucho.

»González Stephan, B. y Andermann.J. (eds.) (2006). Galería del progreso: Museos, exposiciones y cultura visual en América Latina. Rosario, Beatriz Viterbo.

» Greco, M. y Stenner, P. (eds.) (2008). Emotions: A Social Science Reader. Nueva York, Routledge.

» Hernández, F. (1971). El cocodrilo y otros cuentos. Buenos Aires, Centro Editor de América Latina.

» Hernández, J. (2001 [1872]). Martín Fierro. Lois, E y Núñez, Á. (ed. crítica). Madrid, Archivos.

》IIlouz, E. (2009 [1991]). El consumo de la utopía romántica: El amor y las contradicciones culturales del capitalismo. Rodil, M. V. (trad). Madrid, Katz.

"----. (2007). Intimidades congeladas: Las emociones en el capitalismo. Buenos Aires, Katz.

» Isaacs, J. (1867). María.

» Lutz, C. (1988). Unnatural Emotions: Everyday Sentiments on a Micronesian Atoll and Their Challenge to Western Theory. Chicago, University of Chicago Press.

" Macón, C. (2013). SENTIMUS ERGO SUMUS: El surgimiento del "Giro Afectivo" y su impacto en la filosofía política. En Revista Latinoamericana de filosofía política II, Vol. II, núm. 6, pp. 1-32.

" Macón, C. y Solana, M. (eds.) (2015). Pretérito indefinido. Afectos y emociones en las

»aproximaciones al pasado. Buenos Aires, Título.

" Maíz, C. y Fernández Bravo. Á. (eds.) (2009). Episodios en la formación de redes culturales en América Latina. Buenos Aires, Prometeo.

» Martí, J. (1963). Obras completas, 26 vols. La Habana, Editorial Nacional de Cuba.

» Massumi, B. (2002). Parables for the Virtual: Movement, Affect, Sensation. Duke, Durham..

» Matto de Turner, C. (1889). Aves sin nido. Valencia, Sempere y Compañía.

»Mead, M. (1928). Coming of Age in Samoa: A Psychological Study of Primitive Youth for Western Civilization. Nueva York, William Morro \& Company.

» Moraña, M. y Sánchez Prado, I. (2012). El lenguaje de las emociones: Afecto y cultura en América Latina. Madrid, Iberoamericana/Vervuert.

"Ngai, S. (2005). Ugly Feelings. Boston, Harvard University Press.

"Nussbaum, M. C. (2001). Upheavals of Thought. The intelligence of Emotions. Cambridge, Cambridge University Press.

»----. (2004). Hiding From Humanity: Disgust, Shame, and the Law. Princeton, Princeton University Press.

»Peluffo, A. (2016). En clave emocional. Cultura y afecto en América Latina.

» Podalsky, L. (2011). The Politics of Affect and Emotion in Contemporary Latin American Cinema. Nueva York, Palgrave. 
Preciado, B. (2010). Manifiesto Contrasexual. Madrid, Anagrama.

"Reddy, W. M. (2001). The Navigation of Feeling: A Framework for the History of Emotions. Cambridge, Cambridge University Press.

»Reguillo, R. (2011). Prólogo: Pensar desde los bordes: Lo politico y su clave emocional. En Berlant, L. El corazón de la nación. México, FCE.

»Renan, E. (2000). ¿Qué es una nación?. En La invención de la nación: Lecturas de la identidad de Herder a Homi Bhabha. Buenos Aires, Manantial.

»Reyes, A. (1998). El llanto de América. En Obras completas IX. México, FCE.

»Rosenwein, B. H. (2006). Emotional Communities in the Early Middle Ages. Ithaca, Cornell University Press.

"Sarlo, B. (2000). El imperio de los sentimientos: Narraciones de circulación periódica en la Argentina (1917-1927). Barcelona, Norma.

"----. (2012). Signos de pasión: claves de la novela sentimental del Siglo de las luces a nuestros días. Buenos Aires, Biblos.

» Sarmiento, D. F. (1998 [1845]). Facundo. Civilización y Barbarie. Vida de Juan Facundo Quiroga. Mexico, Porrúa.

"Sedgwick, E. K. (2003). Touching Feeling: Affect, Pedagogy, Performativity. Durham/Londres, Duke University Press.

»Spinoza, B. de (1984 [1677]). Ética demostrada según el orden geométrico. Peña, V. (ed.). Madrid, Editoria nacional.

» Stearns, P. N. (1989). Jeaulosy. The Evolution of an Emotion in American History. Nueva York, New York University Press.

» Tausiet, M. y Amelang, J. S. (eds.) (2009). Accidentes del alma. Las emociones en la Edad Moderna. Madrid, Abada.

» Ticineto Clough, P. y Halley, J. (2007). The Affective Turn: Theorizing the Social. Durham, Duke University Press.

"Williams, R. (1977). Structures of Feeling. En Marxism and Literature. Oxford, Oxford University Press.

»Zabludovsky, y Elias, N. (2012). Prólogo. En El proceso de la civilización: investigaciones sociogenéticas. México, FCE. 
